\title{
Local Release of Antibiotics for Surgical Site Infection Management Using High-Purity Calcium Sulfate: An In Vitro Elution Study
}

\author{
Sean S. Aiken,, John J. Cooper, ${ }^{1}$ Hannah Florance, ${ }^{2}$ Matthew T. Robinson, ${ }^{2}$ and Stephen Michell ${ }^{2}$
}

\begin{abstract}
Background: The aim of this study was to characterize the elution of four antibiotics from pharmaceuticalgrade calcium sulfate beads and show that the eluted antibiotics retained efficacy.

Methods: Calcium sulfate was combined with gentamicin, tobramycin, vancomycin, or rifampicin (ratio: $20 \mathrm{~g}$ of calcium sulfate, to $240 \mathrm{mg}, 500 \mathrm{mg}, 900 \mathrm{mg}$, and $600 \mathrm{mg}$ of antibiotic, respectively). Three grams of beads were immersed in $4 \mathrm{~mL}$ of sterile phosphate-buffered saline (PBS) at $37^{\circ} \mathrm{C}$. At each time point $(4,8,24 \mathrm{~h} ; 2,7$, $14,28,42 \mathrm{~d}$ ), eluates were removed for analysis by liquid chromatography-mass spectrometry. The antimicrobial efficacy of antibiotics combined with calcium sulfate beads after $42 \mathrm{~d}$ was tested by a modified KirbyBauer disc diffusion assay.

Results: All samples showed a generally exponential decay in the eluted antibiotic concentration. At the first time point, both gentamicin and tobramycin had eluted to a peak concentration of approximately $10,000 \mathrm{mcg} / \mathrm{mL}$. For rifampicin, the peak concentration occurred at $24 \mathrm{~h}$, whereas for vancomycin, it occurred at $48 \mathrm{~h}$. The eluted concentrations exceeded the minimum inhibitory concentration for common periprosthetic joint infection pathogens for the entire span of the 42 study days. Mass spectrometry confirmed all antibiotics were unchanged when eluted from the calcium sulfate carrier. Antimicrobial efficacy was unaltered after $42 \mathrm{~d}$ in combination with calcium sulfate at $37^{\circ} \mathrm{C}$.

Conclusions: Pharmaceutical-grade calcium sulfate has the potential for targeted local release of tobramycin, gentamicin, vancomycin, and rifampicin over a clinically meaningful time period.
\end{abstract}

\begin{abstract}
A N AREA GAINING INCREASING INTEREST for treating bone and soft tissue infections is the controlled release and local delivery of antibiotics from suitable carriers [1-6]. The benefits of "local release" are substantial and include the ability to provide high local concentrations of antibiotic, many times the minimum inhibitory concentration (MIC) [7], with serum concentrations and associated toxicity remaining low [8-10]. It has been suggested that such high concentrations can even penetrate a biofilm [11]. Research indicates that the outcomes of treating bacterial infections with surgical debridement and the short-term placement of antibiotic-loaded cement have been significantly better than those of surgical treatment alone [12]. The local release of antibiotics in combination with systemic therapy is superior to systemic therapy alone in two-stage arthroplasty revision procedures [13].

One of the most adopted materials for local release of antibiotics is polymethylmethacrylate (PMMA) [14,15].
\end{abstract}

However, this material has a number of significant disadvantages. It is a dense, acrylic, and non-resorbing material, which generally must be removed in a second surgical procedure when its function has been fulfilled to avoid becoming a nidus for future infection [16]. Also, it can release subinhibitory concentrations of drugs over an extended implantation period, and bacteria adherent to PMMA cement thus can acquire resistance to the loaded antibiotic because of long exposure to the sub-inhibitory concentrations [17-19]. In addition, PMMA is not suitable for delivery of thermosensitive antibiotics because of the high temperatures generated during PMMA curing [20,21].

Fully bioabsorbable carriers are now the subject of extensive investigation [22-24]. One such material is calcium sulfate, with recent literature discussing its application in combination with antibiotics [16,25,26], including its safe and efficacious use in infected soft tissue sites [27].

\footnotetext{
${ }^{1}$ Biocomposites Ltd., Keele Science Park, Staffordshire, United Kingdom.

${ }^{2}$ Biosciences, College of Life and Environmental Sciences, University of Exeter, Exeter, United Kingdom.
} 
There is a variety of data in the literature on the in vitro elution rates of various antibiotics from a number of carrier materials [23,28-38], including calcium sulfate [20,39-43]. Literature reports a large variation in the in vitro experimental methods used to determine antibiotic elution. Methods differ in the quantity of material tested, the nature by which the sample is presented to the solution (single small beads $[20,42,43]$ and larger cast cylinders $[40,41])$, the volume and nature of the solution into which the sample is immersed, the volume removed for analysis, and the eluent sampling intervals. It is difficult to correlate in vitro with in vivo conditions.

When investigating the elution of tobramycin from calcium sulfate beads, McLaren et al. [44] considered the assumptions made when approximating surgical site conditions. Those authors estimated that many orthopedic surgical sites have a volume of $100 \mathrm{~mL}$ or less and are commonly filled with as much as 40 antibiotic-loaded calcium sulfate/antibiotic beads of unspecified size. Despite this observation, this in vitro elution study immersed only eight beads in $20 \mathrm{~mL}$ of buffered saline. In their discussion, the need for additional investigation to characterize elution from calcium sulfate during the first $24 \mathrm{~h}$ of implantation was noted.

The current study was designed to establish an experimental protocol that mimics more closely the clinical situation for the material-antibiotic combinations in order to provide elution data of greater clinical relevance. This protocol was then used to determine the elution profiles of four commonly used antibiotics, namely tobramycin, gentamicin, vancomycin, and rifampicin over a period of $42 \mathrm{~d}$, the typical time period over which calcium sulfate beads would be resorbed fully in vivo $[45,46]$.

\section{Materials and Methods}

\section{Experimental design}

The in vitro conditions were intended to mimic the implantation of calcium sulfate beads in a small bone defect. Two bead sizes were investigated. Beads were hemispherical with diameters of either $3 \mathrm{~mm}$ or $6 \mathrm{~mm}$.

The volume fill of $3 \mathrm{~g}$ of $3-\mathrm{mm}$ calcium sulfate beads is $3.4 \mathrm{~mL}$, whereas the volume fill of $3 \mathrm{~g}$ of $6-\mathrm{mm}$ calcium sulfate beads is $4.2 \mathrm{~mL}$. The use of this quantity of beads for the elution experiment was comparable to the quantity of beads used clinically in small bone defects/voids of approximately $4 \mathrm{~mL}$ volume, a size comparable to that observed in osteomyelitis [25,47]. The addition of $4 \mathrm{~mL}$ of phosphatebuffered saline (PBS), pH 7.4, to the elution vessel enabled a sufficient volume of liquid for eluent collection whilst en- suring fluid coverage of the beads, mimicking a small bone void, with the limited volume available for both bead placement and subsequent filling of the interstitial space between the beads (e.g., blood, serous fluid, extracellular matrix).

Considering a dynamic surgical site environment, balancing bleeding and capillary leaking at the site with resorption with venous and lymphatic return, a partial exchange of eluent was used (1.5-mL daily exchange of a total volume of $4 \mathrm{~mL}$ ) in an attempt to represent the antibiotic concentrations present in a relatively stable surgical site more accurately [44].

A concern when incorporating antibiotics into a delivery vehicle is the effect of the carrier material on the antibiotic and the potential for it to cause chemical changes to the antibiotic that may affect both its antimicrobial efficacy and the biological response. The elution concentrations in this study were determined using liquid chromatography-mass spectrometry (LC-MS), a powerful technique with high sensitivity and selectivity. An advantage of using this technique was that the identity of the eluted antibiotics could be confirmed in order to determine if there had been any change in the antibiotic chemistry. To identify any change in the antimicrobial properties of the antibiotics following combination with calcium sulfate over $42 \mathrm{~d}$, the aged and nonaged beads were tested using a modified Kirby-Bauer disc diffusion assay [48-50].

\section{Preparation of beads}

Ten-milliliter kits containing $20 \mathrm{~g}$ of pharmaceutical-grade calcium sulfate alpha-hemihydrate powder (CSH; Stimulan ${ }^{\circledR}$, Biocomposites Ltd, Keele, Staffordshire, United Kingdom) were used to prepare the antibiotic-impregnated beads; $20 \mathrm{~g}$ of $\mathrm{CSH}$ was mixed with $6 \mathrm{~mL}$ of gentamicin sulfate solution (40 mg/mL, Hospira UK Ltd., London, UK) for gentamicinloaded beads; For the tobramycin-containing beads, $20 \mathrm{~g}$ of $\mathrm{CSH}$ was mixed with $500 \mathrm{mg}$ of tobramycin sulfate powder (Gallipot Inc., now Fagron US, St. Paul, MN) and blended thoroughly prior to the addition of $6 \mathrm{~mL}$ of sterile water. For the vancomycin-containing beads, $20 \mathrm{~g}$ of CSH was mixed with $1 \mathrm{~g}$ of vancomycin hydrochloride powder (Hospira UK) and blended thoroughly prior to the addition of $6 \mathrm{~mL}$ of sterile water. For the beads containing rifampicin, $20 \mathrm{~g}$ of $\mathrm{CSH}$ was mixed with $600 \mathrm{mg}$ of rifampicin powder (Sigma-Aldrich UK, Dorset, United Kingdom) and blended thoroughly prior to the addition of $6 \mathrm{~mL}$ of sterile water.

In each case, all components were mixed thoroughly for 30 to $60 \mathrm{sec}$ to form a smooth paste, which was pressed into 3.0or $6.0-\mathrm{mm}$ diameter cavities in the flexible mold (Fig. 1A).
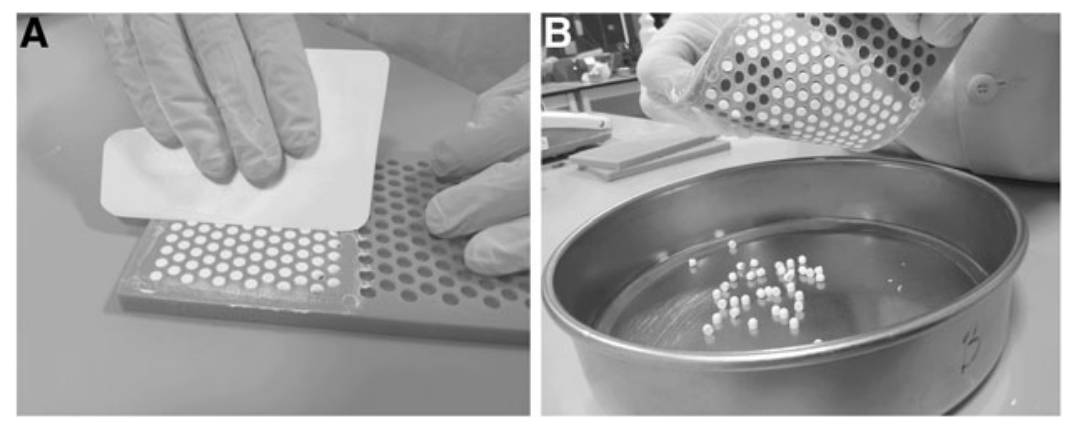

FIG. 1. Preparation of calcium sulfate beads using flexible mold. 
The beads were left undisturbed for 30 to $60 \mathrm{~min}$ to hydrate and set according to the reaction:

$$
\mathrm{CaSO}_{4} 1 / 2 \mathrm{H}_{2} \mathrm{O}+11 / 2 \mathrm{H}_{2} \mathrm{O}=\mathrm{CaSO}_{4} 2 \mathrm{H}_{2} \mathrm{O}
$$

When set hard, the beads were removed from the mold by flexing it (Fig. 1B). By using thorough mixing in the preparation of the beads, a homogenous mixture of antibiotic and CSH was achieved. Therefore, the concentration of antibiotic per weight of beads could be calculated (Table 1).

\section{Antibiotic elution from $3 \mathrm{~g}$ of beads}

Three grams $( \pm 0.05 \mathrm{~g})$ of each antibiotic and bead size combination (Table 1) was placed in sterile 7-mL tubes, to which $4 \mathrm{~mL}$ of sterile PBS was added. Tubes were incubated in the dark at $37^{\circ} \mathrm{C}$. The time points chosen to determine elution were 4,8 , and $24 \mathrm{~h}$ and $2,7,14,28$, and $42 \mathrm{~d}$. At each time point, three $0.5-\mathrm{mL}$ samples of the PBS were removed for analysis by LC-MS. The same amount of fresh PBS was replaced and the tubes returned to the incubator.

The three individual eluate samples from each vial were frozen immediately at $-20^{\circ} \mathrm{C}$. All eluate samples were stored under these conditions until analyzed together at the end of the final elution time point of $42 \mathrm{~d}$. Prior to LC-MS analysis, the eluates were defrosted on ice. The $0.5-\mathrm{mL}$ aliquots were transferred to fresh tubes. These were centrifuged at $4^{\circ} \mathrm{C}$, and then $0.2 \mathrm{mcm}$ from each sample was syringe-filtered directly into glass autosampler vials to remove any particulate matter. The autosampler holding the vials was held at $4^{\circ} \mathrm{C}$.

Antibiotic solutions prepared from the same stocks as those used to prepare the beads were used as standards for assay development and quantification by LC-MS. Quantification was carried out using a triple quadrupole (QQQ) mass spectrometer (MS) coupled to a 1200 series rapid-resolution highperformance liquid chromatography (HPLC) stack (Agilent Technologies, Microlease, Morrisville, NC). Depending on the concentration, samples were analyzed either neat or diluted to ensure values fell within the linear range of the standard curves. Concentrations were calculated from peak areas using standard curves developed from dilutions of antibiotic prepared to known concentrations.
The HPLC conditions were as follows: Buffer A was 5\% acetonitrile (ACN), $0.1 \%$ formic acid and $\mathrm{B}$ was $95 \% \mathrm{ACN}$, $0.1 \%$ formic acid. The gradient was held with $0 \% \mathrm{~B}$ for $2 \mathrm{~min}$ before increasing linearly to $100 \%$ over 4 min. The $100 \% \mathrm{~B}$ was maintained for a further $2 \mathrm{~min}$ before rapid requilibration in $100 \%$ A. The flow rate was constant at $0.3 \mathrm{~mL} / \mathrm{min}$.

The gas temperature in the source was $325^{\circ} \mathrm{C}$ with a flow rate of $9 \mathrm{~L} / \mathrm{min}$. The nebulizer pressure was 35 pounds per square inch and the capillary voltage $3.5 \mathrm{kV}$. Fragmentor and collision energy voltages were optimized for each antibiotic and are listed in Table 2 along with the relevant multiple reaction-monitoring (MRM) values.

\section{Quantification by LC-MS}

Standard curves of each antibiotic were used to determine the limits of detection (LoD) and linear ranges of detection using peak areas. Test solutions were prepared for which the concentrations were unknown to the user. These were run twice, once directly and once spiked with a known concentration of the relevant antibiotic, ensuring peak areas fell within the linear range. This ascertained whether ion suppression would prevent quantification directly from a standard curve without further dilution. If there was no ion suppression, eluates were analyzed directly from a standard curve comprising a minimum of five concentrations. Otherwise, samples were diluted to obtain a concentration low enough to prevent this problem.

\section{Antibiotic stability}

In elution experiments for antibiotics combined with calcium sulfate published previously [20], samples were frozen for a maximum of $10 \mathrm{~d}$ before quantifying the antibiotic content so as to minimize the risk of the antibiotics degrading over time. As samples in this experiment were stored frozen for a maximum of $42 \mathrm{~d}$, an antibiotic control was used, whereby a sample of the antibiotic solution used for LC-MS calibration and testing was kept aside and processed alongside the eluate samples (both incubation and freezing). The results were checked against the original standard curve to confirm the stability of the antibiotic. Therefore, tubes containing $4 \mathrm{~mL}$ of prepared antibiotics at the maximum concentration shown in Table 1 were incubated alongside the elution study samples.

Table 1. Antibiotics and Their Concentrations

\begin{tabular}{|c|c|c|c|c|c|}
\hline \multirow[b]{2}{*}{ Antibiotic } & \multirow[b]{2}{*}{$C S H(g)$} & \multirow[b]{2}{*}{ Bead diameter (mm) } & \multicolumn{3}{|c|}{ Antibiotic Concentration } \\
\hline & & & $m g / 10 m L \mathrm{CaSO}_{4}$ & $m g / 3 g \mathrm{CaSO}_{4}$ & Max. $m g / m L^{\mathrm{a}}$ \\
\hline Gentamicin sulfate solution $(40 \mathrm{mg} / \mathrm{mL})$ & $\begin{array}{l}20 \\
20\end{array}$ & $\begin{array}{l}3.0 \\
6.0\end{array}$ & 240 & 28 & 7.00 \\
\hline Tobramycin sulfate & $\begin{array}{l}20 \\
20\end{array}$ & $\begin{array}{l}3.0 \\
6.0\end{array}$ & 500 & 57 & 14.25 \\
\hline Vancomycin hydrochloride & $\begin{array}{l}20 \\
20\end{array}$ & $\begin{array}{l}3.0 \\
6.0\end{array}$ & 900 & 100 & 25.00 \\
\hline Rifampicin & $\begin{array}{l}20 \\
20\end{array}$ & $\begin{array}{l}3.0 \\
6.0\end{array}$ & 600 & 68 & 17.00 \\
\hline
\end{tabular}

${ }^{\mathrm{a}}$ Calculated as the maximum achievable concentration of antibiotic when $3 \mathrm{~g}$ of prepared beads are placed in $4 \mathrm{~mL}$ of phosphate-buffered saline. 
Table 2. Fragmentor and Collision Energy Voltages Optimized for Each Antibiotic

\begin{tabular}{lcclcc}
\hline Antibiotic & Precursor $\mathrm{m} / \mathrm{z}$ & Product $\mathrm{m} / \mathrm{z}$ & Polarity & Fragmentor $(V)$ & Collision Energy $($ V) \\
\hline Gentamicin & 478.3 & 156.9 & Positive & 120 & 20 \\
Tobramycin & 468.3 & 162.8 & Positive & 120 & 20 \\
Vancomycin & $1,448.4$ & 1402.2 & Negative & 135 & 35 \\
Rifampicin & 823.4 & 150.8 & Positive & 135 & 30 \\
\hline
\end{tabular}

\section{Antibiotic efficacy}

In order to determine the preservation of antimicrobial efficacy of the antibiotics in the beads over the 42-d period, samples of antibiotic-loaded beads were prepared as described above. These beads were tested using a modified Kirby-Bauer disc diffusion assay [48-50]. The control was beads either aged or non-aged and prepared without antibiotic. The beads were prepared either immediately prior to testing or stored for $42 \mathrm{~d}$ at $37^{\circ} \mathrm{C}$ in sealed sterile moistureimpermeable foil pouches prior to testing. Zone of inhibition (ZOI) testing of aged and non-aged beads containing the antibiotics and antimicrobial susceptibility testing discs (AST discs) (tobramycin $30 \mathrm{mcg}$, vancomycin $30 \mathrm{mcg}$, rifampicin $5 \mathrm{mcg}$, and gentamicin $200 \mathrm{mcg}$ (Oxoid Ltd, a division of ThermoFisher Scientific, Basinstoke, Hamphire, United Kingdom) was performed in triplicate against Staphylococcus aureus American Type Culture Collection strain (ATCC) 6538 and S. epidermidis ATCC 12228. Tryptone soy agar (TSA) plates were seeded $(0.2 \mathrm{~mL})$ with a suspension of the relevant organism containing approximately $10^{8}$ colony-forming units $[\mathrm{CFU}] / \mathrm{mL}$. The plates were transferred to an incubator operating at $35 \pm 2^{\circ} \mathrm{C}$ for $30 \mathrm{~min}$. The plates were removed from the incubator and the beads or discs placed on the surface. The plates were then incubated at $35 \pm 2{ }^{\circ} \mathrm{C}$ for $24 \mathrm{~h}$, after which time, they were removed from the incubator and examined for any clear zones around the test sample. Zones were measured from the edge of the bead or control disc to the zone perimeter, calculating the total zone diameter including the sample. Images were taken of the plates.

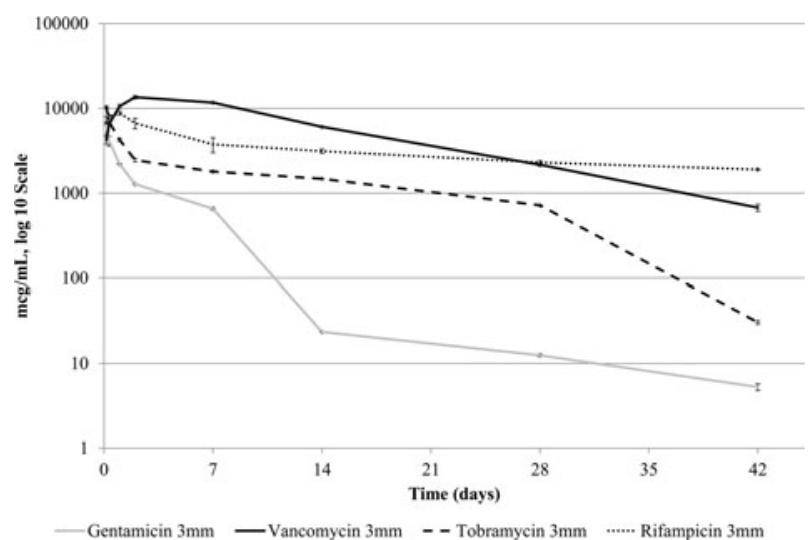

FIG. 2. Concentration ( $\mathrm{mcg} / \mathrm{mL})$ of gentamicin, vancomycin, tobramycin, or rifampicin determined by liquid chromatography-mass spectrometry over time in phosphatebuffered saline removed from tubes containing $3 \mathrm{~g}$ of 3-mm beads. Bars represent standard error of the mean.

\section{Results}

\section{Quantification by LC-MS}

Correlation of standard curves $\left(\mathrm{R}^{2}\right)$ for all antibiotics was $\geq 0.975$. Figures 2 and 3 show the mean antibiotic concentrations of eluate samples taken from tubes containing $3 \mathrm{~g}$ of beads. All samples showed a generally exponential decay in eluted antibiotic concentration with respect to time. At the first, 4-h, time point, gentamicin had eluted to peak concentrations (3-mm beads $6,400 \mathrm{mcg} / \mathrm{mL}$, $6-\mathrm{mm}$ beads $10,400 \mathrm{mcg} / \mathrm{mL})$. The elution of gentamicin was maintained at a higher level for a longer duration with the 6-mm beads. By comparison, the 3-mm beads showed a sharp drop in detectable concentrations at $14 \mathrm{~d}$.

Elution of tobramycin followed the same pattern, with peak concentrations at $4 \mathrm{~h}(3-\mathrm{mm}$ beads $10,300 \mathrm{mcg} / \mathrm{mL}, 6-\mathrm{mm}$ beads $6,700 \mathrm{mcg} / \mathrm{mL}$ ). However, higher elution was achieved with the 3-mm beads.

For rifampicin, the peak concentration occurred at the 24-h time point (3-mm beads $88,000 \mathrm{mcg} / \mathrm{mL}, 6-\mathrm{mm}$ beads $15,200 \mathrm{mcg} / \mathrm{mL}$ ), whereas for vancomycin, it occurred at $48 \mathrm{~h}$ (3-mm beads $13,500 \mathrm{mcg} / \mathrm{mL}, 6-\mathrm{mm}$ beads $10,400 \mathrm{mcg} / \mathrm{mL}$ ).

For 3-mm beads, rifampicin and vancomycin maintained a higher concentration in the PBS than tobramycin and gentamicin from $8 \mathrm{~h}$ onwards. Rifampicin 6-mm beads initially maintained a higher concentration $(8 \mathrm{~h}$ to $48 \mathrm{~h})$, whereas vancomycin was at a higher concentration at $7 \mathrm{~d}$ and $14 \mathrm{~d}$.

Significant concentrations of eluted antibiotic were noted at $42 \mathrm{~d}$ (gentamicin: $3-\mathrm{mm}$ beads $5 \mathrm{mcg} / \mathrm{mL}, 6-\mathrm{mm}$ beads $6 \mathrm{mcg} / \mathrm{mL}$; tobramycin: $3-\mathrm{mm}$ beads $30 \mathrm{mcg} / \mathrm{mL}, 6-\mathrm{mm}$ beads

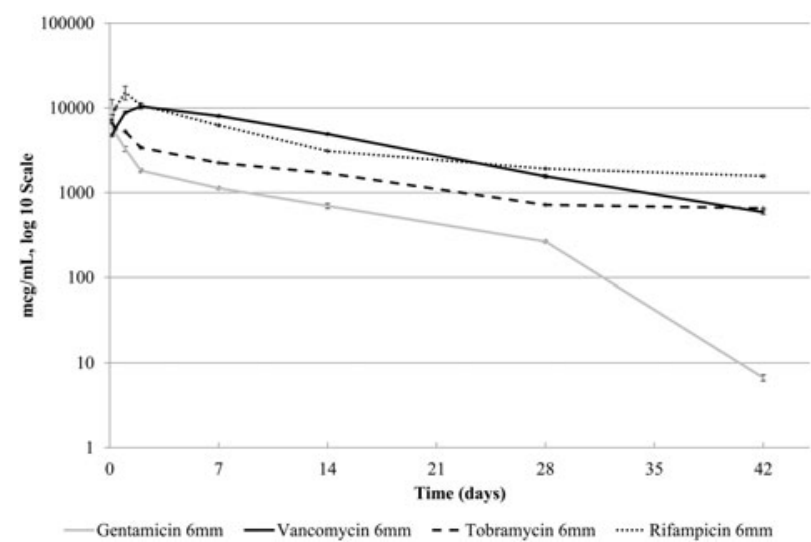

FIG. 3. Concentration $(\mathrm{mcg} / \mathrm{mL})$ of gentamicin, vancomycin, tobramycin, or rifampicin determined by liquid chromatography-mass spectrometry over time in phosphatebuffered saline removed from tubes containing $3 \mathrm{~g}$ of $6-\mathrm{mm}$ beads. Bars represent standard error of the mean. 
TAble 3. Zone of InHibition Results FOR STAPHYLOCOCCUS AUREUS

\begin{tabular}{|c|c|c|c|c|c|c|}
\hline \multirow[b]{4}{*}{ Tobramycin beads } & \multicolumn{6}{|c|}{ Zone size $(\mathrm{mm})$} \\
\hline & \multicolumn{6}{|c|}{ Total zone size including sample, edge of the bead, or control disk to the zone perimeter } \\
\hline & \multicolumn{3}{|c|}{ Non-aged } & \multicolumn{3}{|c|}{ Aged } \\
\hline & $18.0, \quad 7.7$ & $19.0,8.0$ & $19.0, \quad 7.7$ & $19.0, \quad 7.8$ & $19.0, \quad 7.8$ & $19.0, \quad 7.8$ \\
\hline Vancomycin beads & $18.0, \quad 5.7$ & $18.0,6.0$ & $18.0, \quad 6.4$ & $16.3, \quad 5.5$ & $16.3, \quad 5.5$ & $17.0, \quad 6.0$ \\
\hline Rifampicin beads & $30.0,12.6$ & $30.0,13.0$ & $30.0,12.4$ & $30.0,12.3$ & $29.0,11.5$ & $30.0,12.3$ \\
\hline Gentamicin beads & $20.0,8$ & $20.0, \quad 8.0$ & $19.8, \quad 8.0$ & $19.7, \quad 7.3$ & $19.7, \quad 7.3$ & $20.0, \quad 7.5$ \\
\hline Unloaded beads (control) & No zone & No zone & No zone & No zone & No zone & No zone \\
\hline Tobramycin disc $30 \mathrm{mcg}$ & $16.7, \quad 5.9$ & $15.3,4.9$ & $16.8, \quad 5.9$ & NT & NT & NT \\
\hline Vancomycin disc $30 \mathrm{mcg}$ & $13.8, \quad 4.0$ & $13.7,4.0$ & $13.7, \quad 3.5$ & NT & NT & NT \\
\hline Rifampicin disc $5 \mathrm{mcg}$ & $25.5,^{\mathrm{a}} 9.5$ & $25.3,{ }^{\mathrm{a}} 9.3$ & $25.0,^{\mathrm{a}} 9.0$ & NT & NT & NT \\
\hline Gentamicin disc $200 \mathrm{mcg}$ & $16.0, \quad 5.0$ & $16.0,5.0$ & $16.0, \quad 5.0$ & NT & NT & NT \\
\hline
\end{tabular}

${ }^{a}$ Available zone interpretation of Susceptible (S) in accordance with Clinical Laboratory Standards Insitute Performance Standards for Antimicrobial Susceptibility Testing [70].

$\mathrm{NT}=$ not tested.

$650 \mathrm{mcg} / \mathrm{mL}$; vancomycin: 3 -mm beads $670 \mathrm{mcg} / \mathrm{mL}, 6-\mathrm{mm}$ beads $590 \mathrm{mcg} / \mathrm{mL}$; rifampicin: $3-\mathrm{mm}$ beads $1900 \mathrm{mcg} / \mathrm{mL}$, 6-mm beads $1,600 \mathrm{mcg} / \mathrm{mL})$.

\section{Antibiotic stability}

Analysis of stability standards confirmed stability of the antibiotics at the chosen concentration over the 42-d sampling period.

\section{Antibiotic efficacy}

Results from the ZOI testing indicated that antimicrobial efficacy of all the antibiotics was unaffected after $42 \mathrm{~d}$ at $37^{\circ} \mathrm{C}$ in the loaded beads (Tables 3 and 4). The zones of inhibition observed around the beads tested were larger than those observed with the AST discs for each antibiotic.

\section{Discussion}

This study was intended to address experimental design and the clinical use of the material-antibiotic combinations in order to provide elution results of greater clinical relevance.
The experimental parameters described above were intended to mimic a small bone defect/void of approximately $4 \mathrm{~mL}$ in a relatively stable environment. The model does have some limitations. Whilst the chosen parameters are intended to mimic an in-vivo scenario in terms of quantity of material used, volume of eluent, and eluent exchange, the model does not take into account factors such as clot formation, which will have an effect on the diffusion of antibiotic into the surgical site, and protein binding [51], which will affect the antimicrobial efficacy of the antibiotics released into the extracellular matrix. Silverman et al. [52] attempted to mimic the in-vivo environment by determining the effect of clot formation around gentamicin-impregnated $\beta$-tricalcium phosphate granules on antibiotic elution, with results showing that clotted blood slowed drug release.

Common pathogens reported in orthopaedic infections are S. aureus [53-55], S. epidermidis [55,56], coagulasenegative staphylococci [54], and Pseudomonas aeruginosa $[54,55]$. The eluted concentrations of all four antibiotics tested, for both the 3-mm and 6-mm beads, exceeded reported MICs for pathogens commonly observed in periprosthetic joint infections [57-68] for the 42-d study period. This

Table 4. Zone of Inhibition Results for STAPHYLOCOCCUS EPIDERMIDIS

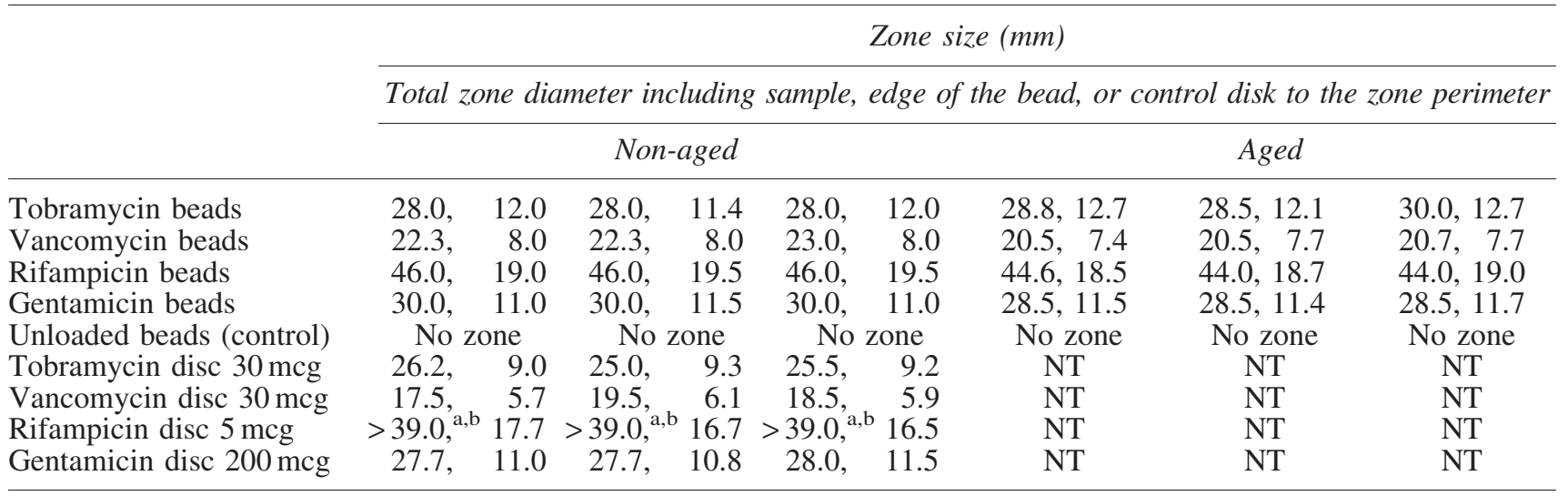

${ }^{a}$ Available zone interpretation of Susceptible (S) in accordance with Clinical Laboratory Standards Insitute Performance Standards for Antimicrobial Susceptibility Testing [70].

${ }^{\mathrm{b}}$ Zones starting to merge; therefore, impossible to measure accurately.

$\mathrm{NT}=$ not tested. 
suggests that the study material has potential for effective local antimicrobial therapy when placed in a stable environment for as long as $42 \mathrm{~d}$. For surgical sites with higher fluid transfer, the elution period may be reduced.

Care should be taken when drawing comparisons of antibiotic elution between different studies, as the design of elution experiments can have an effect on the concentrations and duration of antibiotic release. Two studies that have investigated elution from a single bead of calcium sulfate showed a shorter duration of elution than was demonstrated by the results of this experiment. Miclau et al. [43] investigated the elution of tobramycin from individual beads of calcium sulfate containing $25,000 \mathrm{mcg} / \mathrm{bead}$ and found that $17 \%$ of the antibiotic load was released in $24 \mathrm{~h}$, with only trace amounts remaining at three weeks.

Wichelhaus et al. [20] investigated the elution of vancomycin, teicoplanin, gentamicin, and clindamycin from individual calcium sulfate beads. Initial release was especially high for gentamicin and clindamycin, at greater than $25,000 \mathrm{mcg} / \mathrm{bead}$ within the first $24 \mathrm{~h}$. Elution kinetics demonstrated an initial elution phase, with beads releasing approximately $45 \%$ of the glycopeptide antibiotic and about $80 \%$ of gentamicin and clindamycin within the first $24 \mathrm{~h}$. A more gradual second phase was observed over a further $10 \mathrm{~d}$.

Recently, Roberts et al. [69] reported elution of vancomycin from individual calcium sulfate beads for as long as $20 \mathrm{~d}$ from vancomycin-loaded beads and as long as $40 \mathrm{~d}$ from beads loaded with both vancomycin and tobramycin. The ability of the presence of tobramycin to prolong vancomycin elution was noted.

In comparison, results from this study demonstrate elution of gentamicin, tobramycin, vancomycin, and rifampicin in significant amounts for as long as $42 \mathrm{~d}$. However, it must be noted that our elution results were from a larger number of beads per vial (a total combined weight of $3 \mathrm{~g}$ ) and a different sampling regimen than in many published elution studies, and therefore caution should be exercised when directly comparing results.

The molecular fingerprint of the antibiotics was measured using their mass and products of fragmentation. If they had degraded in any way, such as by oxidation or hydrolysis, the molecular fingerprint would change. Any structural change in the antibiotics would be unlikely to lead to identical ion breakup. No change was observed in the molecular fingerprints for the antibiotics for the duration of the elution experiment in both the elution samples and the antibiotic stability standards over the 42-d period of testing.

The Kirby-Bauer disc diffusion assay is used routinely to test bacterial sensitivity to antibiotics. The modification of this technique has been successful previously in determining the shelf-life of antibiotic-impregnated calcium sulfate beads [49]. The results of this previous study suggested that calcium sulfate beads containing either vancomycin or tobramycin, when stored at room temperature and ambient humidity, appeared to maintain their antimicrobial characteristics for at least $120 \mathrm{~d}$. The disc diffusion data presented herein indicate that the antimicrobial efficacy of gentamicin, tobramycin, vancomycin, and rifampicin remained unchanged after combination with calcium sulfate and storage for $42 \mathrm{~d}$ at $37^{\circ} \mathrm{C}$. The combined observations from the LC-MS analysis and the modified Kirby-Bauer assay demonstrated that the antibiotics eluted from the calcium sulfate beads were unchanged throughout the 42-d period and confirm that their antimicrobial efficacy was maintained.

An antimicrobial, or other therapeutic agent, can be present in a water-based delivery matrix in essentially three forms, all dependent on the relative hydrophilicity/hydrophobicity and solubility: (1) Simply dissolved in the aqueous phase; (2) present as a solid dispersion throughout the matrix; or (3) adsorbed onto the surface of the solid component of the matrix. The differences in the elution profiles for each antibiotic tested here may be attributable to differences in their solubility in the calcium sulfate matrix. Differences were observed in the elution between the 3-mm and 6-mm beads. Relative elution of both vancomycin and rifampicin were different for the two beads sizes over the first $48 \mathrm{~h}$ of testing. Also, elution of gentamicin was maintained at a higher level for 6-mm beads for the first $28 \mathrm{~d}$ of testing. The differences in elution profiles are unclear and may be attributable to a number of factors. The 6-mm and 3-mm beads have different surface-to-volume ratios, with the smaller beads having a higher ratio by a factor of eight. Therefore, the $3-\mathrm{mm}$ beads have a larger surface area and a reduced diffusion path for each antibiotic from the center to the surface of each bead. However, this must be balanced against the solubility of the antibiotic, its molecular weight, and its potential for binding to the calcium sulfate. Further studies are required to determine the mechanism of release kinetics for antibiotics from calcium sulfate.

\section{Conclusions}

The study data from the LC-MS analysis were confirmed by the ZOI results from the Kirby-Bauer analysis. The data presented here indicate that synthetic pharmaceutical-grade calcium sulfate may have useful application as a delivery matrix for the targeted local release of tobramycin, gentamicin, vancomycin, and rifampicin and may be an effective tool in the management of bone and soft tissue infections. Calcium sulfate has the potential to deliver effective local antibiotic concentrations for a period of at least $42 \mathrm{~d}$ without affecting the chemical nature and antimicrobial efficacy of these antibiotics.

\section{References}

1. Su WY, Chen YC, Lin FH. A new type of biphasic calcium phosphate cement as a gentamicin carrier for osteomyelitis. Evid Based Complement Alternat Med 2013; 2013:801374.

2. Sanders J, Mauffrey C. Long bone osteomyelitis in adults: Fundamental concepts and current techniques. Orthopedics 2013;36:368-375.

3. Maier GS, Roth KE, Andereya S, et al. Elution characteristics of gentamicin and vancomycin from synthetic bone graft substitutes. Open Orthop J 2013;7:624-629.

4. Kluin OS, van der Mei HC, Busscher HJ, Neut D. Biodegradable vs non-biodegradable antibiotic delivery devices in the treatment of osteomyelitis. Expert Opin Drug Deliv 2013;10:341-351.

5. Lipsky BA, Kuss M, Edmonds M, et al. Topical application of a gentamicin-collagen sponge combined with systemic antibiotic therapy for the treatment of diabetic foot infections of moderate severity: A randomized, controlled, multicenter clinical trial. J Am Podiatr Med Assoc 2012;102: 223-232. 
6. Hodgkiss-Harlow KD, Bandyk DF. Antibiotic therapy of aortic graft infection: Treatment and prevention recommendations. Semin Vasc Surg 2011;24:191-198.

7. Kanellakopoulou K, Galanopoulos I, Soranoglou V, et al. Treatment of experimental osteomyelitis caused by methicillinresistant Staphylococcus aureus with a synthetic carrier of calcium sulphate (Stimulan) releasing moxifloxacin. Int J Antimicrob Agents 2009;33:354-359.

8. Wahl P, Livio F, Jacobi M, et al. Wound fluid and serum concentrations of vancomycin after local therapy with calcium sulphate as carrier material. J Bone Joint Surg 2012; 94B:79.

9. Wahl P, Livio F, Jacobi M, et al. Systemic exposure to tobramycin after local antibiotic treatment with calcium sulphate as carrier material. Arch Orthop Trauma Surg 2011;131:657-662.

10. Noor S, Bridgeman P, David M, et al. The use Osteoset-T in the treatment of chronic osteomyelitis of the tibia following exogenous trauma: A review of 22 patients at a regional trauma centre. J Bone Joint Surg 2013;95B:4.

11. Winkler H. Rationale for one-stage exchange of infected hip replacement using uncemented implants and antibiotic impregnated bone graft. Int J Med Sci 2009;6:247-252.

12. Garvin KL, Hanssen AD. Infection after total hip arthroplasty: Past, present, and future. J Bone Joint Surg 1995; 77A:1576-1588.

13. Cabrita HB, Croci AT, Camargo OP, Lima AL. Prospective study of the treatment of infected hip arthroplasties with or without the use of an antibiotic-loaded cement spacer. Clinics (Sao Paulo) 2007;62:99-108.

14. Buchholz HW, Engelbrecht H. [Depot effects of various antibiotics mixed with Palacos resins] (Ger). Chirurg 1970; 41:511-515.

15. Regis D, Sandri A, Samaila E, et al. Release of gentamicin and vancomycin from preformed spacers in infected total hip arthroplasties: Measurement of concentrations and inhibitory activity in patients' drainage fluids and serum. Scientific World J 2013;2013:752184.

16. Gitelis S, Brebach GT. The treatment of chronic osteomyelitis with a biodegradable antibiotic-impregnated implant. J Orthop Surg (Hong Kong) 2002;10:53-60.

17. van de Belt $H$, Neut $D$, Schenk $W$, et al. Infection of orthopedic implants and the use of antibiotic-loaded bone cements: A review. Acta Orthop Scand 2001;72:557-571.

18. Anagnostakos K, Hitzler P, Pape D, et al. Persistence of bacterial growth on antibiotic-loaded beads: Is it actually a problem? Acta Orthop 2008;79:302-307.

19. Neut D, van de Belt H, van Horn JR, et al. Residual gentamicinrelease from antibiotic-loaded polymethylmethacrylate beads after 5 years of implantation. Biomaterials 2003;24:1829-1831.

20. Wichelhaus TA, Dingeldein E, Rauschmann M, et al. Elution characteristics of vancomycin, teicoplanin, gentamicin and clindamycin from calcium sulphate beads. J Antimicrob Chemother 2001;48:117-119.

21. Mousset B, Benoit MA, Delloye C, et al. Biodegradable implants for potential use in bone infection: An in vitro study of antibiotic-loaded calcium sulphate. Int Orthop 1995;19:157-161.

22. Kuiper JW, Brohet RM, Wassink S, et al. Implantation of resorbable gentamicin sponges in addition to irrigation and debridement in 34 patients with infection complicating total hip arthroplasty. Hip Int 2013;23:173-180.

23. Chen DW, Liao JY, Liu SJ, Chan EC. Novel biodegradable sandwich-structured nanofibrous drug-eluting membranes for repair of infected wounds: An in vitro and in vivo study. Int J Nanomedicine 2012;7:763-771.

24. El-Husseiny M, Patel S, MacFarlane RJ, Haddad FS. Biodegradable antibiotic delivery systems. J Bone Joint Surg 2011;93B:151-157.

25. McKee MD, Li-Bland EA, Wild LM, Schemitsch EH. A prospective, randomized clinical trial comparing an antibiotic-impregnated bioabsorbable bone substitute with standard antibiotic-impregnated cement beads in the treatment of chronic osteomyelitis and infected nonunion. J Orthop Trauma 2010;24:483-490.

26. McKee MD, Wild LM, Schemitsch EH, Waddell JP. The use of an antibiotic-impregnated, osteoconductive, bioabsorbable bone substitute in the treatment of infected long bone defects: Early results of a prospective trial. J Orthop Trauma 2002;16:622-627.

27. Swords K, Martinez DR, Lockhart JL, Carrion R. A preliminary report on the usage of an intracorporal antibiotic cast with synthetic high purity $\mathrm{CaSO}_{4}$ for the treatment of infected penile implant. J Sex Med 2013;10:1162-1169.

28. Weiss BD, Weiss EC, Haggard WO, et al. Optimized elution of daptomycin from polymethylmethacrylate beads. Antimicrob Agents Chemother 2009;53:264-266.

29. Squire MW, Ludwig BJ, Thompson JR, et al. Premixed antibiotic bone cement: an in vitro comparison of antimicrobial efficacy. J Arthroplast 2008;23:110-114.

30. McLaren RL, McLaren AC, Vernon BL. Generic tobramycin elutes from bone cement faster than proprietary tobramycin. Clin Orthop Relat Res 2008;466:1372-1376.

31. McLaren AC, McLaren SG, Hickmon MK. Sucrose, xylitol, and erythritol increase PMMA permeability for depot antibiotics. Clin Orthop Relat Res 2007;461:60-63.

32. Nelson CL, Griffin FM, Harrison BH, Cooper RE. In vitro elution characteristics of commercially and noncommercially prepared antibiotic PMMA beads. Clin Orthop Relat Res 1992;(284):303-309.

33. Perry AC, Rouse MS, Khaliq Y, et al. Antimicrobial release kinetics from polymethylmethacrylate in a novel continuous flow chamber. Clin Orthop Relat Res 2002;(403):4953.

34. Phillips H, Boothe DM, Shofer F, et al. In vitro elution studies of amikacin and cefazolin from polymethylmethacrylate. Vet Surg 2007;36:272-278.

35. Schiefer UR, Heiss C, Dingeldein E, et al. [Elution kinetics and antimicrobial effects of gentamicin- and clindamycinloaded bone cements in vitro] (Ger). Z Orthop Unfall 2008;146:92-98.

36. Urabe K, Naruse K, Hattori H, et al. In vitro comparison of elution characteristics of vancomycin from calcium phosphate cement and polymethylmethacrylate. J Orthop Sci 2009;14:784-793.

37. Samuel S, Mathew BS, Veeraraghavan B, et al. In vitro study of elution kinetics and bio-activity of meropenemloaded acrylic bone cement. J Orthop Traumatol 2012;13: 131-136.

38. Watts AE, Nixon AJ, Papich MG, et al. In vitro elution of amikacin and ticarcillin from a resorbable, self-setting, fiber reinforced calcium phosphate cement. Vet Surg 2011;40:563-570.

39. Atilla A, Boothe HW, Tollett M, et al. In vitro elution of amikacin and vancomycin from impregnated plaster of Paris beads. Vet Surg 2010;39:715-721.

40. Kanellakopoulou K, Panagopoulos P, Giannitsioti E, et al. In vitro elution of daptomycin by a synthetic crystallic 
semihydrate form of calcium sulfate, Stimulan. Antimicrob Agents Chemother 2009;53:3106-3107.

41. Panagopoulos $\mathrm{P}$, Tsaganos $\mathrm{T}$, Plachouras $\mathrm{D}$, et al. In vitro elution of moxifloxacin and fusidic acid by a synthetic crystallic semihydrate form of calcium sulphate (Stimulan). Int J Antimicrob Agents 2008;32:485-487.

42. Parker AC, Smith JK, Courtney HS, Haggard WO. Evaluation of two sources of calcium sulfate for a local drug delivery system: A pilot study. Clin Orthop Relat Res 2011;469:3008-3015.

43. Miclau T, Dahners LE, Lindsey RW. In vitro pharmacokinetics of antibiotic release from locally implantable materials. J Orthop Res 1993;11:627-632.

44. McLaren AC, McLaren SG, Nelson CL, et al. The effect of sampling method on the elution of tobramycin from calcium sulfate. Clin Orthop Relat Res 2002;(403):54-57.

45. Cierny G III, DiPasquale D. Comparing OsteoSet and Stimulan as antibiotic-loaded, calcium sulfate beads in the management of musculoskeletal infection. Presented at the 19th Annual Open Scientific Meeting of the Musculoskeletal Infection Society,; 7-8th August 2009, San Diego, CA.

46. Cai X, Han K, Cong X, et al. The use of calcium sulfate impregnated with vancomycin in the treatment of open fractures of long bones: A preliminary study. Orthopedics 2010:152-157.

47. Patwardhan S, Shyam AK, Mody RA, et al. Reconstruction of bone defects after osteomyelitis with nonvascularized fibular graft: A retrospective study in twenty-six children. J Bone Joint Surg 2013;95A:e561-e566, S1.

48. Bauer AW, Kirby WM, Sherris JC, Turck M. Antibiotic susceptibility testing by a standardized single disk method. Am J Clin Pathol 1966;45:493-496.

49. Armstrong DG, Stephan KT, Espensen EH, et al. What is the shelf life of physician-mixed antibiotic-impregnated calcium sulfate pellets? J Foot Ankle Surg 2003;42:302-304.

50. Boyle VJ, Fancher ME, Ross RW Jr. Rapid, modified Kirby-Bauer susceptibility test with single, highconcentration antimicrobial disks. Antimicrob Agents Chemother 1973;3:418-424.

51. Schmidt S, Rock K, Sahre M, et al. Effect of protein binding on the pharmacological activity of highly bound antibiotics. Antimicrob Agents Chemother 2008;52:3994-4000.

52. Silverman LD, Lukashova L, Herman OT, et al. Release of gentamicin from a tricalcium phosphate bone implant. J Orthop Res 2007;25:23-29.

53. Saadatian-Elahi M, Teyssou R, Vanhems P. Staphylococcus aureus, the major pathogen in orthopaedic and cardiac surgical site infections: A literature review. Int J Surg 2008;6:238-245.

54. Geipel U. Pathogenic organisms in hip joint infections. Int $\mathrm{J}$ Med Sci 2009;6:234-240.

55. Arciola CR, An YH, Campoccia D, et al. Etiology of implant orthopedic infections: A survey on 1027 clinical isolates. Int J Artif Organs 2005;28:1091-1100.

56. Antoci V Jr, Adams CS, Parvizi J, et al. The inhibition of Staphylococcus epidermidis biofilm formation by vancomycin-modified titanium alloy and implications for the treatment of periprosthetic infection. Biomaterials 2008;29:4684-4690.

57. Lowy FD, Walsh JA, Mayers MM, et al. Antibiotic activity in vitro against methicillin-resistant Staphylococcus epidermidis and therapy of an experimental infection. Antimicrob Agents Chemother 1979;16:314-321.
58. Sabath LD, Garner C, Wilcox C, Finland M. Susceptibility of Staphylococcus aureus and Staphylococcus epidermidis to 65 antibiotics. Antimicrob Agents Chemother 1976;9:962969.

59. Tam VH, Kabbara S, Vo G, et al. Comparative pharmacodynamics of gentamicin against Staphylococcus aureus and Pseudomonas aeruginosa. Antimicrob Agents Chemother 2006;50:2626-2631.

60. Vandenesch F, Naimi T, Enright MC, et al. Communityacquired methicillin-resistant Staphylococcus aureus carrying Panton-Valentine leukocidin genes: Worldwide emergence. Emerg Infect Dis 2003;9:978-984.

61. Britt MR, Garibaldi RA, Wilfert JN, Smith CB. In vitro activity of tobramycin and gentamicin. Antimicrob Agents Chemother 1972;2:236-241.

62. Day CA, Marceau-Day ML, Day DF. Increased susceptibility of Pseudomonas aeruginosa to ciprofloxacin in the presence of vancomycin. Antimicrob Agents Chemother 1993;37:2506-2508.

63. Kawano J, Shimizu A, Saitoh Y, et al. Isolation of methicillin-resistant coagulase-negative staphylococci from chickens. J Clin Microbiol 1996;34:2072-2077.

64. Qu Y, Daley AJ, Istivan TS, et al. Antibiotic susceptibility of coagulase-negative staphylococci isolated from very low birth weight babies: Comprehensive comparisons of bacteria at different stages of biofilm formation. Ann Clin Microbiol Antimicrob 2010;9:16.

65. Rybak MJ, Cappelletty DM, Moldovan T, et al. Comparative in vitro activities and postantibiotic effects of the oxazolidinone compounds eperezolid (PNU-100592) and linezolid (PNU-100766) versus vancomycin against Staphylococcus aureus, coagulase-negative staphylococci, Enterococcus faecalis, and Enterococcus faecium. Antimicrob Agents Chemother 1998;42:721-724.

66. Fowler CE, Soothill JS, Oakes L. MICs of rifampicin and chloramphenicol for mucoid Pseudomonas aeruginosa strains are lower when human lactoferrin is present. J Antimicrob Chemother 1997;40:877-879.

67. Kernt K, Martinez MA, Bertin D, et al. A clinical comparison of two formulations of tobramycin $0.3 \%$ eyedrops in the treatment of acute bacterial conjunctivitis. Eur J Ophthalmol 2005;15:541-549.

68. Young LS, Hewitt WL. Activity of five aminoglycoside antibiotics in vitro against gram-negative bacilli and Staphylococcus aureus. Antimicrob Agents Chemother 1973; 4:617-625.

69. Roberts R, McConoughey SJ, Calhoun JH. Size and composition of synthetic calcium sulfate beads influence dissolution and elution rates in vitro. J Biomed Mater Res B Appl Biomater 2013;102:667-673.

70. Clinical Laboratory Stamdard Institute. Performance Standards for Antimicrobial Susceptibility Testing; TwentySecond Informational Supplement. CLSI document M100-S22. Wayne, PA: CLSI; 2012.

Address correspondence to: Dr. Sean S. Aiken Biocomposites Ltd, Keele Science Park Keele, Staffordshire, ST5 5NL, United Kingdom

E-mail: sa@biocomposites.com 